\title{
Filosofía de la religión
}

\author{
Invitación a una tarea actual
}

\author{
JOSÉ GÓMEZ CAFFARENA
}

Instituto de Filosofia, CSIC, Madrid

Ha sido afortunado el reciente abandono de la «teología natural» por la «filosofía de la religión ": ésta es más respetuosa de lo específico religioso y más genuina filosofía. Debe venir tras otros abordajes (historiográfico, sociológico, fenomenológico). Puede subrayar «religión » (bien como teoría globalizadora de las explicaciones científicas, bien como complemento hermenéutico de la fenomenologia). Si, más bien, subraya "filosofía", será empirista, «idealistaobjetiva» 0 «idealista de la libertad» (tipos de Dilthey). Su cultivo es buen antídoto de fanatismos de uno u otro sentido.

«Filosofía de la religión» no es una denominación tradicional. Se da por primera vez, en cuanto sabemos, a finales del siglo xvm y en lengua alemana. ${ }^{1}$ Lo cual es comprensible: tras la Aufklärung había circunstancias (ya, en cierto modo, anticipadas en el deísmo inglés y francés) que invitaban a hacer de la religión objeto explícito de reflexión filosófica. Como es bien conocido, el título quedó consagrado en las Vorlesungen über Religionsphilosophie de Hegel (1821 a 1831). ${ }^{2}$

No carece de significación el que nos hallemos ante algo relativamente reciente. Por supuesto, el origen real no coincide simplemente con el nominal. Dejando las múltiples implicaciones históricas de religión y filosofía (para las que sólo sería aplicable en sentido muy laxo), el título «Filosofía de la religión» debe, sin duda, aplicarse a los Dialogues concerning Natural Religion de Hume y a Die Religion innerhalb der Grenzen der blossen Vernunft de Kant. Es correcto extenderlo a algunos otros escritos del xvirr (de Spinoza, Lessing, Herder...). ${ }^{3}$ Pero en ese siglo domina aún más generalmente la relación de filosofía y «Dios" que encontramos en la "teología natural" de Wolff, de algún modo heredera de la tradición escolástica. ${ }^{4}$

El cambio supone el reconocimiento explícito de que «Dios» pertenece en principio al ámbito religioso, algo no puesto de relieve en la tradición anterior. Por los avatares conocidos de la historia del pensamiento occidental, había más bien sufrido un cierto secuestro filosófico. Una - comprensible - voluntad de acreditar racionalmente la fe monoteísta mediante "pruebas de la existencia de Dios" y elucubraciones sobre su 
"esencia» había ido transformando a Dios en el Absoluto. Muchos creyentes, de Pascal a Kierkegaard, declararon no reconocerlo. Sin llegar hasta ahí, muchos otros se felicitarán de que hoy se lo restituya a lo religioso. Como muchos filósofos se felicitarán de la clarificación general que eso supone.

Se puede decir que el gran desarrollo de la filosofía de la religión sólo ha tenido lugar en el siglo xx -algo ya perceptible incluso por la proliferación de libros con ese título. Esta eclosión se enmarca en un hecho de más amplitud. En nuestro siglo, y coincidiendo con una primera madurez del desarrollo de las ciencias positivas, la filosofía busca más cautamente su estatuto. Sin renunciar al proyecto de una "filosofía primera» -ensayado de varias maneras-, ha encontrado un puesto urgente y socialmente reconocido en la forma de las filosofias sectoriales, que se enuncian mediante genitivo objetivo ( «filosofía de-»). En doble dirección. Ante todo como metateoria de la ciencia ("filosofía de la física", "de la biología «...). También como reflexión sobre un sector de la realidad, en el que también se reconocen saberes científicos. Así, «filosofía de la naturaleza»...; y, en la realidad humana, «filosofía del lenguaje», "filosofía de la historia», «filosofía del arte»... Es entre estas últimas filosofías sectoriales donde (al menos, de entrada) se sitúa la filosofía de la religión.

Destaquemos el carácter muy explícitamente reflexivo que asume el filosofar en estos ejercicios sectoriales cuando su objeto es una parte de la experiencia humana: lejos de constituirla, la supone y vuelve sobre ella (para hacer lo que puede llamarse una «reconstrucción crítica»). Es importante en relación con las ambigüedades antes aludidas. Al hacerse «filosofía de la religión", la filosofía proclama su voluntad de respetar como específico el hecho religioso. Tratará de comprenderlo correctamente, antes de preguntarse por su «verdad" y de tomar partido a su respecto.

Pero estoy suponiendo que hay efectivamente un específico «hecho religioso". Y ya ello podría ser cuestionable. En todo caso, la primera preocupación de una filosofía de la religión metódicamente correcta será preguntarse por esa supuesta facticidad y sus características, hasta contar con una suficiente descripción. Tendrá también que recoger la aportación de las disciplinas científicas pertinentes. A estos dos puntos voy, por mi parte, a dirigir la atención en primer lugar, aunque de modo sumario y elemental.

\section{El hecho religioso y los ángulos primarios de su estudio}

1.1. Lo externo y lo interno («expresión/experiencia»). De «hecho religioso" hablamos, en primer lugar, por cuanto encontramos una serie de objetividades del ámbito cultural, pasado y presente, que nos sentimos autorizados a encuadrar bajo una rúbrica común y pensamos no podrían 
ser simplemente subsumidas bajo otras. Tales son los templos y los objetos de culto, las prácticas rituales, los gestos simbólicos asociados con ellas, las creencias a que están referidas... Pienso que es innegable su realidad y especificidad. Pero conviene añadir en seguida dos observaciones. No están siempre claras sus fronteras con otros «hechos culturales», como los que forman el arte o la moral. Y cuando queremos clarificar esas fronteras y precisar lo irreductible de lo religioso objetivo, no podemos hacerlo sin recurrir a suponer subyacente una específica intencionalidad subjetiva.

Ello conecta con lo siguiente. En un segundo sentido, puede hablarse de "hecho religioso" como hecho de la conciencia, es decir, como tipo específico de vivencias o experiencias interiores, que han tenido y tienen los humanos. Para quien las tiene, son un hecho, aunque del orden de la subjetividad y sólo indirectamente (por sus efectos) asequible a los otros.

La relación entre ambos niveles de hecho religioso es fácil de establecer: lo cultural-externo puede tenerse por expresión de lo experiencialinterno. Esto último es, entonces, la clave de aquella intencionalidad que las objetividades culturales hacen suponer subyacente y que permite clasificarlas como "religiosas". Pienso que no hay que tener recelo ante esta apelación a lo subjetivo. La hacemos en casos análogos. En lo artístico, por ejemplo, clasificamos como tales determinados objetos culturales (estatuas, sinfonías...) en el supuesto tácito de que son reales determinadas vivencias específicas tanto de sus creadores como de sus contempladores. Incluso, quien no tenga las vivencias del caso puede sin difícultad reconocer como «artísticas" o "religiosas» las objetividades correspondientes, sabiendo incluye indirectamente, en su referente, vivencias ajenas. Lo objetivo y lo subjetivo se necesitan dialécticamente. Pues tampoco son concebibles vivencias puras sin ningún tipo de expresión.

1.2. Las religiones en su historia. Para avanzar, concretando esta primera abstracción, el camino más cauto es el que otorga un primado metódico a lo externo. Eso lleva inmediatamente a hablar por lo pronto de religiones en plural. «Una religión» es un sistema simbólico expresivo determinado (que arguye, según lo dicho, unas vivencias). Hay que proceder inductivamente, con método comparativo, si queremos llegar a generalizaciones válidas. Voces críticas recientes han denunciado como etnocéntrica la facilidad con que estudiosos cristianos escriben sobre «religión», sin advertir que no hacen sino colocar bajo un título unitario aquello en lo que encuentran alguna semejanza con lo cristiano. ${ }^{5} \mathrm{La}$ denuncia, pienso, toca un peligro real; y en todo caso hay que contar con que las fronteras son imprecisas. Pero, por otra parte, el estudio (científico o filosófico) necesita aventurarse al uso del genérico «religión». Se 
eludirá suficientemente el peligro si se mantiene el debido relieve de lo diferencial.

En este camino hay que recoger cuidadosamente la aportación de todos los saberes hoy acreditados sobre lo religioso. Y hay, desde luego, que comenzar por la aportación más imprescindible y rica, que es la historiográfica. Con anticipos desde la Antigücdad, la «historia de las religiones lleva ya más de un siglo de desarrollo fecundo y proporciona un repertorio muy copioso de datos. Para reunirlos descriptivamente, no ha necesitado una definición previa muy elaborada. El historiador puede trabajar con una sola pre-noción elemental y debe no dejar de recoger ningún dato presumiblemente religioso, situándolo en el conjunto cultural del que forma parte.

Como fruto de esa aportación, nos es hoy posible una reconstrucción ordenada del pasado y presente religioso de la humanidad. No será enteramente ocioso evocarla aquí en sus rasgos más esenciales, pues constituye, en definitiva, el último referente de todo el discurso metateórico que intento.

$\mathrm{Y}$ en orden, precisamente, a evitar en lo posible el etnocentrismo, veo mejor partir de lo culturalmente más cercano. No es dudable que "religión" hemos llamado ante todo al cristianismo, con cuyos dos mil años de historia se relaciona tan estrechamente nuestra cultura. Desde este punto de partida, aparecen en seguida también como "religión " otros dos sistemas simbólicos, muy afines e históricamente implicados: el yahvismo y el islam. Bastante mayor es, reconozcamos, el desnivel que hay que salvar para extender la denominación «religión » a los grandes sistemas simbólicos de la India (hinduismo, budismo, jainismo) y de China (taoísmo y confucianismo). ${ }^{6}$ Como es mayor también para las «religiones mistéricas» del Oriente medio (apogeo en los últimos siglos antes de nuestra era). Pero que también tal extensión es correcta lo muestran las semejanzas que han llevado a largas discusiones sobre el influjo de dichos sistemas en el cristianismo naciente. Por otra parte, que también fue religio la romana no sólo sería excesiva paradoja linguística el negarlo, sino olvido de la conciencia que en su momento hubo de que el cristianismo la desplazaba en su terreno. ${ }^{7}$

Pero de la romana no pueden separarse el politeísmo griego y los otros indoeuropeos, tan afines entre sí. $^{8}$ Admitido lo cual, y habiendo entrado de ese modo en el ámbito de las «religiones étnicas", será ya improcedente negar en principio la denominación «religiosa» a los demás sistemas simbólicos que han cumplido y cumplen función análoga en los miles de grupos étnicos de la historia humana, incluidos los menos desarrollados (ágrafos).

Los historiadores proceden con toda naturalidad a la inversa de mi rebuscada evocación retrospectiva. Incluso los más reflexivamente cons- 
cientes de las dificultades de su labor no renuncian a la idea de una cierta unidad de la historia y unos suficientes rasgos comunes de la «religión ${ }^{7}$. Denuncian la ingenua ambición evolucionista (vigente a comienzos de nuestro siglo), que creía poder explicar todo el hecho religioso desde sus formas más primitivas. Pero, aunque presentan prevalentemente sus estudios en monografías por civilizaciones (egipcia, mesopotámica...), no renuncian a su ordenación en una cierta secuencia temporal progresiva, desde las formas más arcaicas (donde lo religioso está apenas diferenciado del resto cultural), pasando por las sobrevenidas con la agricultura y por el nacimiento de las "civilizaciones superiores" (los momentos típicamente politeístas), hasta las religiones «de tendencia universal». Este último segmento histórico les merece especial subrayado, pues en él la religión se separa más del resto de lo cultural y da el máximo relieve a la religiosidad personalizada. Puede llamarse «tiempo-eje» a los siglos vIII-IV antes de nuestra era: de él arrancan las religiones que aún hoy reúnen más adeptos. ${ }^{10}$

1.3. Ciencias de la religión. El discurso historiográfico - directopide, en todo caso, metalenguajes complementarios. Tal será, últimamente, el de la filosofía de la religión. Pero, en un nivel todavía más cercano a los datos empíricos, hay que acoger la mediación de las construcciones que hoy solemos llamar «ciencias del hombre".

Etnología, psicología y sociología han desarrollado en nuestro siglo importantes capítulos sobre lo religioso. " En el escaso margen de que aquí dispongo y buscando sólo lo elementalmente suficiente, voy a prescindir de las peculiaridades, en método y resultados, de cada una de esas disciplinas, para esbozar sólo lo que pienso puede tenerse por su aportación común. En cuanto teoría científica positiva, dirigida a lo religioso en el conjunto de la realidad humana (individual y social), participan las "ciencias de la religión" de la voluntad explicativa que es constitutiva de todo proyecto científico. ${ }^{12}$ Tratan de explicar lo religioso como factor antropológico, es decir, en su correlación con otros factores. Ahí radica también su límite. Prescindirán de cualquier "juicio de valor" sobre la verdad de la religión. Y ni siquiera tendrán que hacer central como objeto suyo la específica intencionalidad que subyace a las objetividades religiosas. (Aunque tampoco podrán dejar de tenerla en cuenta como en oblicuo y, en esa medida, incorporar algún elemento de "comprensión", como vio bien el padre de la sociología contemporánea, Max Weber.) ${ }^{13}$

¿Será posible, también aquí, una evocación de lo más esencial de los resultados adquiridos por las ciencias de la religión? Obviamente, en este caso sólo podrá tratarse de un destacado muy selectivo de algunos rasgos - que no aspirará, por tanto, a ser aceptado como resumen objetivo. Aun así, vale la pena intentarlo. 
El concepto clave puede ser «universo simbólico». La sociología de la religión lo declara necesario para la decisiva función antropológica de la legitimación de las instituciones; los individuos humanos no son (correlativamente) socializados sino mediante la asimilación a su propia vida consciente del «universo simbólico» del grupo, que les permite encontrar "sentido» a su existencia ${ }^{14}$ y les es precioso en el "negociar su identidad $\gg{ }^{15}$ Fue E. Durkheim quien inició esta manera de ver, a propósito de «las formas elementales de la vida religiosa " ${ }^{16}$ Vista así y en rigor, la «religión» es coextensiva con la vida social y verdaderamente humana.

Sin devaluar la aportación durkheimiana, parece preferible una estrategia conceptual que no identifique tan simplemente «religión» con «universo simbólico legitimador». Este último podría, mejor, tenerse por un concepto genérico, que incluya como la especie más destacada a la religión propiamente dicha. Pero admitir tal corrección es pedir que la noción de "religión" de las ciencias del hombre - que es básicamente "funcional», es decir, descriptiva de la función (individual o social) del sistema simbólico en cuestión-incorpore algo de "sustantivo", es decir, alguna nota que haga referencia a lo que la religión es y no sólo a su función. El mismo Durkheim introducía, de hecho, en su definición, el término "sagrado". ${ }^{17}$ Es interesante porque nos devuelve a la necesidad (ya señalada) de tomar en consideración, junto a lo objetivo, la intencionalidad. Ahora bien, reconocer esa necesidad equivale a reconocer un límite a la voluntad explicativa del proyecto científico; y sugiere algo así como un «hueco epistemológico" para un proyecto complementario, puramente "comprensivo", de la intencionalidad religiosa: el que a continuación vamos a considerar.

1.4. Fenomenología de la religión. Tal proyecto ha ido recibiendo cuerpo en el segundo tercio de nuestro siglo bajo el título «Fenomenología de la religión». Inicialmente, puede reconducirse al pequeño pero genial libro de Rudolf Otto, Lo Santo, ${ }^{18}$ vigorosa reacción (ante todo) contra el racionalismo de la concepción teológica tradicional de la religión. Al dar relieve en la descripción - devolviéndoles con ello dignidad- a elementos no racionales (emotivos) presentes en la mayoría de las experiencias y expresiones religiosas, las ideas de Otto catalizaron el descontento más general ante otro racionalismo: el de las forzadas y unilaterales síntesis (generalmente evolucionístico-progresistas) con que los historiadores de las religiones de finales del xIX y hasta 1920 habian resumido los datos que presentaban.

Que una tal "vuelta a los hechos» buscara inspiración y crédito en la «vuelta a las cosas» del método fenomenológico de Husserl es muy comprensible. Hay que añadir, en seguida, que la opción por tal patro- 
nazgo metodológico no se tradujo nunca en búsqueda de fidelidad estricta. Algo - valga apostillar - absolutamente comprensible, dada la gran divergencia de los objetivos últimos: mientras que Husserl había intentado refundar una "filosofía primera" con base en la conciencia, la «fenomenología de la religión» sólo buscaba comprender mejor los fenómenos religiosos, intentando la reconstrucción de la intencionalidad subyacente a lo objetivo que describe la historiografía -expuesto a ser malentendido en explicaciones precipitadas.

No son netos ni concordes en las cuestiones de método los «fenomenólogos $»{ }^{19}$ La concentración en la intencionalidad los conduce a una noción más sustantiva de "religión» cifrada generalmente en el concepto "sagrado", con las aclaraciones pertinentes. El rasgo más husserliano a que se apela es la "reducción eidética": para buscar «la esencia» de lo religioso en sus manifestaciones, se hace epoché de todo lo accesorio, así como de las propias convicciones en el tema. Esto último, hay que añadir, no es fácil. Pues, tratándose de reconstruir la intencionalidad de acontecimientos externos a la conciencia del investigador (y, en su mayor parte, dados muy fragmentariamente en los monumentos o escritos del pasado), ha de ponerse en juego una capacidad interpretativa, por fuerza, polivalente. Parece insustituible una elemental «empatía». Y, entonces, ¿no le resultará ésta más asequible a quien tenga convicciones afines? El caso es análogo al del crítico de arte: no podrá serlo quien no tenga, al menos, un básico buen gusto. Hay que conceder que, en uno y otro caso, la epoché sólo puede ser relativa.

Si el estatuto epistemológico queda siempre un tanto impreciso $y$, por ello, discutible y objetable, lo que más puede acreditar a la fenomenología de la religión son sus resultados. Ha servido para conjurar unilateralidades y reduccionismos, para sistematizar datos sin traicionarlos, logrando interpretaciones muy plausibles. No concibo que hoy pueda hacerse buena filosofía de la religión sin tener en cuenta a la fenomenología. Quizá, incluso, debe ser tenida como su primer paso.

Es arriesgado intentar sintetizar esos resultados. En todo caso, no puede suplirse el conocimiento directo de obras como la clásica de G. Van der Leeuw, o esa, no menos clásica, "Morfología de lo sagrado" que Mircea Eliade tituló Tratado de historia de las religiones. ${ }^{20}$ Inspirándome sobre todo en esta última, voy a aventurar a continuación no una síntesis sino una elemental evocación de algunos rasgos básicos de lo religioso visto fenomenológicamente.

No es mucho, hay que observar de entrada, lo que se nos dice cuando se inculca que lo religioso se define por lo «sagrado": si esto no se aclara ulteriormente, podríamos no haber ido más allá del idem per idem; al menos, eso sí, percibimos que estamos ante un irreductible inicial. ${ }^{21}$ Las ciencias de la religión buscan avanzar, según ya hemos visto, por el 
rodeo funcional («universo simbólico», dador de "sentido»). El fenomenólogo intenta el acceso directo, reconstruyendo la intencionalidad de las experiencias de lo sagrado. ¿Lo consigue?

La noción clave, forjada por Eliade, es "hierofanía". Tomada en abstracto, tampoco hace avanzar demasiado. Sí, quizá, en cuanto contiene dos afirmaciones complementarias. 1) «No sabemos si hay algo (objeto, gesto, función fisiológica...) que no haya sido nunca a lo largo de la historia de la humanidad transfigurado en hierofanía». 2) Pero no todo, ni mucho menos, es siempre hierofánico; hay, pues, una dialéctica: «La dialéctica de la hierofanía supone una elección [...]: un objeto resulta sagrado en la medida en que incorpora (es decir, revela) algo "otro" que él mismon. ${ }^{22} \mathrm{Se}$ sugiere, pues, que la experiencia religiosa reconoce no sólo un «ámbito" propio sino, dentro de él, un "polo" que lo constituye - que nunca es heirofania, sino al que remiten las hierofanías-; siguiendo a J. Martín Velasco, podemos apropiarle el nombre de "misterio". ${ }^{23}$

Se introduce así una distancia irreductible, que podría llamarse «trascendencia», pero evitando precisarla en el sentido determinado de ninguna religión concreta; evitando también las connotaciones que el término tiene en contextos filosóficos. Las descripciones fenomenológicas acaban recurriendo a tal término $u$ otros análogos a la hora de expresar lo más esencial de su intento. ${ }^{24}$ Esa caracterización es también útil para deslindar la actitud propiamente religiosa de la magia; esta última (utilitaria y cuasi-técnica) resulta una cierta perversión, por cuanto sólo reconoce la distancia para intentar reducirla. ${ }^{25} \mathrm{La}$ actitud religiosa es adorativa, de puro reconocimiento. Pero hay que añadir que no es, de cualquier modo, «desinteresada». Si renuncia a utilizar concretamente lo sagrado, es porque espera de ello algo superior - «supremo, último [...]». Digamos, con la expresión ya usada, "sentido de la existencia", pero no cualquiera, sino el definitivo. Que es lo que sugiere el término religioso más típico, «salvación». (Que hace alusión a la experiencia humana de la muerte y, más generalmente, de la caducidad y la frustración; pero no de modo exclusivo, pues incluye como núcleo la plenitud deseada. Con lo que la descripción fenomenológica acaba en el deseo como raíz. $)^{26}$

Valga terminar con otra reflexión, que creo afín. Se refiere a la interpretación de lo peculiar de la religiosidad "de tendencia universal", surgida históricamente en el «tiempo-eje». Se hacen patentes con ella dos rasgos en la diacronía de las tradiciones religiosas. Uno es una esencial disimetria: hay experiencias religiosas creativas y.otras que surgen sólo en la estela de aquéllas, inducidas por sus expresiones. Otro es la tendencia a la máxima transparencia de las hierofanías; tendencia que se conjuga dialécticamente con una permanencia de, y aun recaída en, la intransparencia. ${ }^{27}$ 


\section{Filosofía de la religión}

2.1. El proyecto y sus dificultades. Quizá nada evidencia más la necesidad de una auténtica filosofía de la religión que la comparación contrastada de las aportaciones que acabo de reseñar. Resultan insustituibles, pero insuficientes, tanto las ciencias humanas como la fenomenología. Con la atención en lo más objetivo (acontecimientos, comportamientos...), el proyecto científico logra explicar mucho sobre la función antropológi$\mathrm{ca}$ de lo religioso. Buscando directamente reconstruir la intencionalidad subyacente, el proyecto fenomenológico alcanza a comprender algo de lo que es en sí la religión. Las aportaciones no son excluyentes sino complementarias. Pero su complementación deja hueco a otras preguntas: ¿no cabe algún tipo de explicación más allá de lo funcional?, ¿sólo cabe comprender lo que es la religión, sin poder pronunciarse sobre la verdad de lo comprendido?

Una respuesta a esta última pregunta la da, precisamente, la conciencia religiosa. Donde el científico enuncia "el ser humano necesita "sentido" " y lo busca en universos simbólicos de uno u otro tipo; y donde el fenomenólogo reconstruye la intencionalidad que encuentra sentido en este o el otro universo simbólico, sin osar pronunciarse sobre su verdad; el fiel religioso encuentra sentido (éste o aquél), habita con asertividad un sistema simbólico dado. (Un cristiano [consciente] no sólo comprende el cristianismo, sino que lo afirma como verdadero; un musulmán no sólo comprende el islam, sino que lo afirma verdadero...) Pero no puede entregarse en exclusiva la cuestión de la verdad de la religión a la conciencia religiosa. Sería un cierto suicidio de la razón crítica. Puede sospecharse fundadamente que el fiel religioso, siempre de una determinada confesión, no será juez ecuánime entre todas. Tampoco puede suponerse que vaya a tomar (sino indirectamente) postura ante la religión como tal.

Me parece indiscutible que se trata de una problemática típicamente filosófica. La filosofía no puede renunciar a asumirla. No digo con ello que tenga asegurado el éxito; sólo mantengo que debe emprender la tarea y llevarla adelante hasta donde pueda llegar. ${ }^{28}$ No excluyo que la última respuesta pueda ser un respetuoso declinar responder; pero eso valdrá sólo si viene al final. En cualquier caso, la reflexión filosófica habrá aportado no poco sobre la realidad y la función de lo religioso y sobre las condiciones en que sería verdadero; así como sobre la relación que guarde con lo que se tenga, en general, por verdadero.

Pcro, si es fácil argumentar que la filosofía tiene una tarea acerca de la religión, no es igualmente fácil precisar cómo haya de realizarla. Mi manera de hablar ha podido sugerir una homogeneidad en la concepción de objetivos y métodos por parte de los filósofos, que está muy lejos 
de ser real. Lo único que en un artículo como el presente puedo y debo intentar al respecto es dar cuenta de las orientaciones prevalentes en la producción contemporánea puesta bajo la rúbrica «filosofía de la religión». Tratando de encontrar, al menos, una tipificación que haga inteligible su multiplicidad sin traicionarla. El punto clave es, entonces, el del criterio.

Habría uno inmediato y externo, el lingüístico. Obviamente insuficiente, puede servir al menos para una clasificación provisional. Haciendo una división tripartita, podemos decir que hay sendos tercios bien nutridos, el inglés y el alemán, marcados por orientaciones muy generales de la filosofia que se escribe hoy en esas lenguas. Encontramos, en efecto, una específica "filosofía analitica de la religión" -un tipo que se detectaría también con otros criterios y al que daré en su momento la debida atención. En la filosofía de la religión escrita en lengua alemana no es tan fácil encontrar una denominación común; quizá el más apto para una primera descripción global seria: "herencia de la Aufklärung» - comprensible, dado el relieve que ya vimos tuvo la filosofía alemana del s. Xvrrr en el nacimiento mismo del género-. El tercer tèrcio, menos copioso en conjunto, lo forman los libros escritos en lenguas latinas, principalmente en francés. "Hermenéutica" sería, posiblemente, una rúbrica aceptable para no poco de ese lote; aunque no para todo él.

Pero trataré de buscar un criterio menos extrínseco y que sea operativo y fecundo. Pienso que un primero podría venir dado con la diferencia, muy relevante, que proviene de la major o menor sustantividad que, en cada proyecto concreto, tengan, respectivamente, la religión y la filosofia. ${ }^{29}$ Lo ensayaré, pues. Valga recordar previamente que una aplicación metodológica de "tipos» en las ciencias sociales nunca pretende ser descriptiva de la realidad. Dibuja, más bien, polos ideales hacia los que se orienta una multitud de posturas matizadamente diversas, cuya diversidad se espera hacer más inteligible desde la posición que quepa asignar a cada una en relación con los polos dibujados.

\subsection{Ensayo tipológico}

A) Se concede a la religión el carácter más sustantivo. La reflexión filosófica se interesa, entonces, por un conocimiento lo más amplio y exacto de los datos historiográficos; así como por recoger, como punto de partida, la aportación de las ciencias de la religión y de la fenomenología. Por supuesto, siempre para añadir una interpretación crítica y sistemática; de lo contrario, no hay filosofía. Pero, incluso entonces, la filosofía está atenta a no violentar en exceso los datos con su propia aportación.

$B$ ) La filosofía asume una mayor sustantividad suya, sea que la dé simplemente por obvia, sea que la fundamente. Desde ahí dirige su atención a la religión y sus temas primarios; como la dirige al arte, a la cien- 
cia y a los demás sectores culturales; como la dirige a los varios sectores de lo real. Con él propósito, más o menos declarado, de acabar logrando una visión global de la realidad. Y con el presupuesto, más o menos centralmente cultivado, de una "filosofía primera", que da la clave para esa interpretación de todo, incluida la religión. (La cual, añadamos, recibirá con ello una «explicación» diversa de la científica.)

La misma lógica que conduce a estos tipos básicos se prolonga sin dificultad a unas primeras subdivisiones de cada uno de ellos. En el tipo A puede filosofarse, o bien destacando la intencionalidad constitutiva de lo religioso, lo que equivale a asumir la fenomenología de la religión - ya antes recordé que hay filosofías que hacen de ella un primer paso, necesario aunque no suficiente-; o bien, por el contrario, centrando la atención en los comportamientos y en lo objetivo: la filosofía buscará, entonces, la cercanía de las ciencias de la religión. Surge así una polaridad que, teóricamente al menos, es bastante neta.

En el tipo B, es lógico que las subdivisiones sean básicamente las mismas que puedan señalarse como tales para la filosofía en general. Encuentro particularmente operativa la tipificación ternaria propuesta por W. Dilthey en su conocida teoría de las "visiones del mundo ${ }^{30}$ Naturalismo, idealismo de la libertad e idealismo objetivo constituyen tres estilos de filosofar muy característicos y contrapuestos. Mirando la contraposición desde uno de los ángulos posibles, el de la teoría del conocimiento, es claro que puede buscarse la verdad, o bien en la «verificación » o contrastación con la percepción sensorial (empirismo), o bien en la subsunción coherente de cada elemento en la concepción racional total (racionalismo), o bien en una más compleja coherencia y contrastación con la experiencia y estructuras de la consciencia (filosofía de la subjetividad, hoy, quizá, mejor denominable «personalismon). Hume, Hegel, Kant: la tipología diltheyana se acredita por su posible referencia a estos netos modelos típicos. Interesantemente, los mismos que, según ya recordé al principio del artículo, aparecen también con fuerte relieve precisamente en el mismo nacimiento histórico de la filosofía de la religión en el siglo $\mathrm{XvIII}^{31}$

Si nos preguntamos por los rasgos característicos de los tres tipos en esta precisa aplicación, no es difícil ver que el primero emplazará a la religión ante el tribunal de la razón empírica. Se complacerá, con Hume, en hacer «historia natural de la religión»; tratará ulteriormente de pensar, en cercanía a las ciencias del hombre, su razón de ser - su función, pero con tendencia a ver en ella la manifestación verdaderamente fiable de «su ser»-; dará importancia al análisis de sus elementos expresivos (lenguaje, etc.), valorándolos en principio desde criterios generales. Abordará, finalmente, la cuestión de la verdad; para lo cual, seleccionará por economía rasgos decisivos (p. ej., la afirmación «existe Dios» 
de las religiones monoteístas), para examinarlos según reglas de validez generalmente aceptadas para afirmaciones de lo real.

También los otros dos tipos, que Dilthey denominaba «idealistas", emplazan a su modo a la religión ante la razón. Pero es grande la diferencia en el significado de "razón" entre uno y otro (así como respecto al tipo empirista). La "razón», en el «idealismo objetivo», tiende a ser la razón absoluta: totalidad es su palabra clave. Sistemas filosóficos elaborados con ese norte se sienten, comprensiblemente, congeniales con la religión y aun herederos suyos. Cualesquiera sean sus diferencias, religión y filosofía coinciden en el concernimiento con lo definitivo. La historia de las religiones scrá vista como un proceso unitario tendente a culminar en una religión perfecta - incluso si no llega a llamársela "religión absolutan, como Hegel hizo con el cristianismo. La cuestión de la verdad apenas se planteará, pues está resuelta de antemano en la realidad de la razón que filosofa. (E indica, en coherencia con esto, cercanía al tipo «idealista-objetivo» la concesión de validez al «argumento ontológicon.)

En cambio, la «razón» del «idealismo de la libertad» es la razón $h u$ mana; pues prevalece la convicción vivida de que es el sujeto consciente humano quien filosofa, en busca siempre de su «sentido últimon: no sólo la clave del conocer, sino también (y sobre todo), la de su actuar correcto y la de su destino. A la historia de las religiones se la mira selectivamente, valorando en cada religión la afinidad con la disposición integralmente humana («libertad»), primando con ello la «religión racional», aunque sin excluir necesariamente todo lo transracional. En cuanto a la verdad, una razón autocrítica y consciente de sus límites, renuncia en el ámbito religioso al estricto saber, pero concediendo valor de verdad a las aserciones de fe que se apoyen en la confianza otorgada al sujcto humano. Esta filosofía también siente congenialidad con la búsqueda de «sentido de la existencian que subyace a todo lo religioso, y encuentra por ello más fácil acceso al lenguaje simbólico de las religiones.

En mi descripción anterior puede percibirse una no disimulada alusión a Hume, Hegel y Kant. Era oportuna para darme mejor a entender. Pero los rasgos podrían alterarse, dando otras acentuaciones concretas, sin que se perdiera el valor global de la tipología, que me parece grande. Entendiéndola siempre como subordinada a la que propuse en primer lugar, como subdivisión de un tipo que da fuerte sustantividad a la filosofía. ${ }^{32}$

En lo que me queda, trataré de ilustrar con algunos ejemplos pertinentes la tipología propuesta; lejos de toda pretensión de exhaustividad. A lo largo de mis breves exposiciones, iré ofreciendo sugerencias críticas de diverso orden. Me parece natural comenzar por el tipo A, que concede mayor sustantividad a la religión. $\mathrm{Y}$, ante todo, por las reflexiones 
filosóficas que profesan partir de la comprensión: que pueden, genéricamente, ser llamadas "hermenéuticas».

2.3. Desde la comprensión: proyectos hermenéuticos. Antes de referirme a sus más genuinos representantes, creo oportuno fijar la atención en un autor complejo. Neto en la opción teórica por la comprensión de lo religioso en su sustantividad, lo somete después a una reflexión filosófica en la que es muy perceptible el clima de idealismo de la libertad. (Los tipos, ya dije, no tienen realizaciones puras.) El autor en cuestión ha hecho, por otra parte, un análisis minucioso de los métodos y eso le merece mención prioritaria.

Henry Duméry diseñó hace treinta años un ambicioso proyecto de filosofía de la religión, que sólo parcialmente pudo realizar. ${ }^{33} \mathrm{Su}$ libro Critique et Religion está dedicado al método. Tipifica estas cinco posibilidades: $a$ ) «explication», referida a los varios intentos modernos de dar cuenta íntegra de la religión desde la filosofía; $b$ ) "confrontation", donde entiende la elaboración fílosófica paralela, hecha por los escolásticos en subordinación a la teología; c) «anticipation», es decir, el intento kantiano (y otros inspirados en él) de trazar a priori las condicones de la religión válida; $d$ ) "compréhension", el método que se inaugura con la fenomenología. Duméry lo prefiere netamente, frente a los anteriores: $(a)$ y $(c)$ poco fieles al dato religioso, y (b) poco crítico. Pero siente la necesidad de completarlo con una toma de postura crítica. A ésta la llama e), "discrimination", o bien, "análisis reflexivo y crítico" (el que él mismo realiza en sus otros libros).

Para entender el sentido preciso de la articulación de "comprensión "y «discriminación» por la que, en definitiva, opta Duméry -en una fórmula globalmente muy plausible-, hay que advertir que tiene mucho más presente a Husserl y busca mucho más rigor en la aplicación de sus pautas metódicas de cuanto hacen los "fenomenólogos de la religión". Duméry es explicito en propugnar la epoché ("réduction») en el mismo momento "comprensivo". Y no sólo no queda en la «eidética", sino que tampoco en la "fenomenológica», exigiendo se pase, con Husserl, a la "trascendental": es decir, a encontrar fundamentado todo el ámbito vivido en la espontaneidad de la subjetividad. Su aportación más original -y el momento de "discriminación" - llega cuando pide un cuarto nivel de reducción, que conduce a reconocer la misma subjetividad trascendental (finita, humana) como habitada por el Absoluto, por el «Uno transordinal", de quien obtiene su dinamismo unificador ${ }^{34}$ Como es con el Absoluto con quien, por su parte, busca relacionarse la conciencia religiosa, la filosofía de la religión no puede menos de convalidar esa su esencial intencionalidad; con lo que se siente autorizada a exigirle después una severa depuración de las mediaciones simbólicas en que la expresa. 
Pero vayamos ya a filósofos en que aparece más simple la continuidad del filosofar con la búsqueda "fenomenológica" de comprensión. Es obvio empezar la búsqueda entre los mismos fenomenólogos. Y hay, entonces, que mencionar en primer lugar a M. Eliade. Tanto en su «Morfología de lo sagrado" como en varios otros libros, está presente una definida contextura teórica que permite su lectura como filosofía hermenéutica. ${ }^{35}$ Que se dé un solapamiento de reflexión filosófica con el intento de descripción en profundidad que profesa la fenomenología no tiene que extrañar; y la simbiosis metódica puede ser fecunda. Es oportuno recordar que la misma denominación "hermenéutica" proviene, en el campo filosófico, de la preocupación teológica cristiana por la comprensión profunda y actualizada de los textos fundacionales de su tradición religiosa. Cruce de géneros es lo que más resalta en los protocolos de los debates de reflexión religiosa convocados bajo el lema "hermenéutica ${ }^{36}$ La interfecundación de historia, teología y filosofía de la religión es también lo más perceptible en la obra del gran pensador religioso Raimundo Panikkar, que acude también con predilección al título de «hermenéutica». ${ }^{37}$

Pero el autor contemporáneo que más originalmente ha tematizado el método es, sin duda, Paul Ricoeur. Es su entera filosofía la que ha podido denominarse "fenomenología hermenéutica": una reflexión que recoge las consignas metódicas de Husserl $-\mathrm{y}$, a lo que entiendo, su voluntad de hacer "filosofía primera»-, pero se entiende instalada centralmente en el mundo cultural y consciente de que éste, esencialmente simbólico, no se da de modo inmediato sino sólo mediante el paciente trabajo de la interpretación. Aunque no dedicada sistemáticamente a lo religioso, una reflexión así es inevitablemente filosofía de la religión, ya que en el mundo simbólico-cultural ocupa la religión un puesto central.

Ricoeur toma muy en serio la que llama «hermenéutica de la sospecha» (desenmascaradora del autoengaño del sujeto y de las ideologías sociales), pero mantiene la posibilidad de otra «hermenéutica de recolección del sentido" (hacia una "segunda ingenuidad"), que culmina en un sobrio "pensar a partir del símbolo", cauteloso ante toda tentación gnóstica. ${ }^{38}$ No debe disimularse el problema de alcance intersubjetivo que plantea la filosofía hermenéutica de la religión (expresado frecuentemente como "circulo hermenéutico"). ${ }^{39}$ Pero hay que añadir que un problema análogo lo plantean todas las reflexiones filosóficas que incluyen metódicamente una autoimplicación del sujeto, las del tipo diltheyano «idealismo de la libertad».

2.4. Desde la explicación. Una filosofía de la religión del que he llamado tipo A puede hoy también encontrarse en un clima diverso del fenomenológico, el de las ciencias de la religión. Las hipótesis más genera- 
les que se hacen en ese ámbito tienen frecuentemente tal envergadura que podrían bien llamarse «filosóficas». No hay frontera neta, aunque se dé, teóricamente, en el paso de la consideración funcional a otra más «esencial». Pero, ¿no llegan muchos sociólogos a un qué es la religión desde el cómo funciona? Menos relevante es qué pretende explícitamente cada autor que lo que, de hecho, dice. ${ }^{40}$

El propósito, en todo caso, es explícito en Sobre la religión de Alfredo Fierro. Valioso desde muchos puntos de vista, el libro me interesa aquí, sobre todo, como elucidación de la posibilidad metodológica que el autor llama «teoría». El que venga como segundo momento, detrás de otro titulado "descripción», es índice de la sustancialidad concedida al hecho religioso. Tal descripción, aunque reivindica una cierta virtualidad «comprensiva", no se centra en la intencionalijdad religiosa, sino en las realizaciones sociales e históricas. (En el cristianismo, concretamente, las mencionadas con las contraposiciones Iglesia/secta, religión clerical/popular, establecimiento/mesianismo.) Pero prepondera el momento explicativo. "Teoria significa sencillamente conocimiento, tan amplio y tan a fondo como sea posible.» Explica, porque relaciona con lo general. «Sólo se conoce realmente lo religioso cuando se lo conoce en el sistema general de la sociedad y de la cultura. Y, a su vez, este conocimiento de su implantación sociocultural sólo es real si lo religioso es apresado también en sí mismo, en su propia entidad. ${ }^{41}$

¿Es eso filosofía? El autor da una respuesta compleja. La teoría «se apropia el talante de reflexión crítica radical que es propio del discurso filosófico [...]. Pero lleva a cabo su quehacer reflexivo no por los procedimientos tradicionales en el gremio de los filósofos, sino por el camino de las ciencias humanas y sociales». Algo coherente con la acentuación de lo social en la descripción. Fierro prefiere marcar la distancia frente a la "filosofía como disciplina scparada", para integrarse en el ámbito de las ciencias «como su momento hipotético y totalizador, por contraposición con el momento experimental [...]». ${ }^{42}$ Pero, hoy, muchos no conciben de otra manera la filosofía y no cabría, por tanto, excluir de ella a la «teoría" de Fierro. Ejemplifica bien, en mi tipología, la subdivisión contrapuesta a la "hermenéutica» dentro del tipo A. Lo religioso es sustantivo; si la comprensión fenomenológica era mediación para una filosofía hermenéutica, la explicación científica lo es aquí para la "teoría", que la completa desbordándola. ${ }^{43}$

2.5. Desde el empirismo: filosofía analitica de la religión. Pasamos a aquellas filosofías (tipo B) que afrontan el tema religioso desde una estructura propia más sustantiva. Y, siguiendo la pauta diltheyana, vamos, en primer lugar, a las de orientación empirista. En una cultura como la nuestra, tan marcada por la tecnología y el alto aprecio de la positivi- 
dad científica que ella supone y corrobora, será normal encontrar empirismo en muchísimos filósofos. ${ }^{44}$ Pero hay un entero mundo filosófico por excelencia empirista: el de la filosofía «analítica», vigente, sobre todo, en el ámbito anglófono. En ella centro mi rapidísima reseña.

Veo necesario subdividir en dos la filosofía analítica de la religión. Está, por una parte, la larga tradición, aún mayoritaria, de la llamada Philosophical Theology, un trabajo centrado en el clásico tema de la teologia natural (Dios, su existencia y atributos), pero tras el "giro lingüísticon: como problema de la significatividad y posible verdad de las proposiciones que lo expresan. Por otra parte, están los debates, también lingüísticos pero de más alcance, sobre el específico «juego de lenguaje» de la religión, donde hay que destacar el tema del estatuto de la convicción religiosa en relación con el saber más propiamente tal. (Es bastante obvio conectar la inspiración de esta doble tradición con las dos fases sucesivas del pensamiento de Ludwig Wittgenstein.)

Veamos, ante todo, la Philosophical Theology. La historia de su primer y más conocido y reciente periodo está vinculada, en el recuerdo de todos, al «desafío de Flew» y a su subsiguiente disputa ${ }^{45}$ Acertó probablemente Antiseri ${ }^{46}$ al diferenciar dos líneas de respuesta por parte de quienes deseaban eludir la conclusión atea o agnóstica: o revisar la epistemologia empirista hasta devolver a las proposiciones teológicas una (mayor o menor, quizá pequeña) cognitividad $;^{47}$ o bien, buscar un estatuto no cognitivo para ellas. Esta última tendencia no mira a esas solas proposiciones, sino a todo el lenguaje religioso, y no dista ya de la postura «expresivista" que en seguida consideraremos. Pero reseñemos antes un segundo periodo de la Philosophical Theology en que el tema central fue el "argumento ontológico ${ }^{48}$ y un tercero en que se replantean, y con soluciones sorprendentemente asertivas, viejas cuestiones metafísicas que pudieron parecer definitivamente arrumbadas. ${ }^{49}$

La otra tradición analítica, que se centra en el estudio del «juego de lenguaje" propio de lo religioso, ha sido a veces denominada (a partir de los años setenta) «fideísmo wittgensteiniano», en razón de autores $\operatorname{cristianos}^{50}$ que buscaban legitimar lo razonable de la fe cristiana evitando el debate racional suscitado por las filosofías ilustradas. En su reciente libro, Lecciones de filosofía de la religión, Javier Sádaba denuncia justamente la falta de rigor de esa postura, a la vez que mantiene que la posición coherente en la línea del «segundo Wittgenstein" (en la pauta de sus reflexiones sobre La rama dorada de Frazer) es la que, deslindando actitud religiosa de creencia, reclama para la primera un estatuto no cognitivo sino simplemente «expresivo»: el de "una pregunta que no tiene respuesta", que "sólo representa (en el sentido bien preciso de hacerlos presentes) los límites del mundo ${ }^{51}$ Apostillaré que es estimulante 
la coexistencia en nuestra actualidad de estas dos líneas tan dispares dentro de la familia analítica.

2.6. Desde el «idealismo objetivo». Voy a ser particularmente breve en mi referencia a esta orientación. Nuestra cultura la favorece menos y no se puede hablar de una tradición, como en el caso anterior. Pero no faltan brotes, aunque minoritarios; su lugar natural son los escritos de lengua alemana. Resulta un ejemplo típico la reciente Einführung in die Religionsphilosophie del profesor de Nijmegen, Wilhelm Dupré, sin duda, uno de los libros recientes donde la problemática de la filosofía de la religión se presenta con más profundidad y originalidad, sobre una buena base de conocimientos positivos. ${ }^{52}$

Su aportación más sugestiva puede estar en la insistencia en que la disciplina no se tenga por simplemente sectorial, sino que conserve la cercanía e implicación con la filosofía primera que tuvo un tiempo (entendamos: en su prehistoria) y «viene exigida por la convergencia de religión y realidad de la verdad $"{ }^{53}$ Se entiende esto mejor si se admite que «religión» precisamente es «aquella región de la realidad cultural que surge porque se busca llevar a expresión la unidad de realidad y conciencia en su sentido absoluto; y, como tal, es decir, en la forma de símbolos absolutos, integrarla de tal modo en el todo de la humana existencia, que también ésta encuentre su sitio en el Todo de la realidad». ${ }^{54}$

Bajo lo indisimuladamente hegeliano del lenguaje, late aquella preocupación por lo universal que inspiró más generalmente toda la reflexión ilustrada sobre lo religioso, una preocupación que podría hoy tener nueva actualidad. En la noción dada de «religión» se sintetizan las exigencias - funcionalista y sustantivista, respectivamente- de las ciencias humanas y la fenomenología. Asumiéndolas, la filosofía que preconiza Dupré vuelve a reconocerse heredera de la religión, sin desbancarla. Hace que la religión sea algo más que su objeto. Se reconoce en ella, transformándola y transformándose al reconocerse... El proyecto, sin duda, suscitará recelos, así de los más religiosos como de muchos filósofos. Pero hará pensar a unos y otros.

2.7. Desde el «idealismo de la libertad". También seré breve en estas últimas menciones ejemplificadoras. Esta vez no porque no hubiera mucho que reseñar, sino porque se presenta de modos muy varios, poco reductibles a ejemplos realmente típicos. Puede decirse que la relevancia de la subjetividad (a pesar de conocidas impugnaciones) es una nota generalizada del pensamiento filosófico contemporáneo - si bien no tan marcada como la propensión empirista-; sobre todo, en los continuos renacimientos de la cuestión ética. Algo afín al temple básico kantiano resurge una y otra vez, inspirando pensamientos entre 
sí no poco dispares pero coincidentes en la centralidad de la conciencia personal y' su libertad. Ya noté antes que la aportación filosófica más propia de $\mathrm{H}$. Duméry era encuadrable en el idealismo de la libertad; nada extraño si se recuerda su filiación blondeliana. ${ }^{55}$

Pero es, sin duda, Karl Jaspers el pensador del siglo xx que más rasgos encarna del tipo. $\mathrm{Y}$ es La fe filosófica ante la revelación (1962) el libro que nos da su pensamiento maduro en el tema. Resulta inevitable la evocación de La religión en los limites de la mera razón. Hay en Jaspers más neta polémica con la religión "revelada", más amplia reivindicación del primado de la que él llama «fe filosófica». ${ }^{56}$ Como en Kant, también, pero más declaradamente que en Kant, la filosofía se descubre a sí misma religiosa, es decir, nacida como reflexión de una subjetividad irreductible, que sólo llega a ser como tal (mögliche Existenz, Freiheit) cuando se vive frente a la misteriosa "Trascendencian - a la que, sin embargo, no puede dirigirse sino a través de las objetividades transfiguradas simbólicamente, en "cifras" ${ }^{57}$

Si en Jaspers tenemos el ejemplo más neto de filosofía de la religión de inspiración «idealismo de la libertad", una presencia de tal inspiración se percibe más generalmente dondequiera que se dé un primado a la problemática del «sentido de la existencia»: ${ }^{58}$ tal problemática, si bien no está ausente en muchos autores de la línea analítica, no puede en modo alguno reconducirse a los principios empiristas de ésta; tampoco, directa y centralmente, a los racionalistas del idealismo objetivo. Una radical afinidad con el idealismo de la libertad se deja así percibir en los más caracterizados representantes de la «hermenéutica"; pienso, ante todo, en P. Ricoeur. Comprensiblemente: el "mundo cultural», que tal filosofía se da por tarea interpretar, está esencialmente referido a los sujetos, que en él buscan "sentido". La filosofía reencuentra así, como reflexión (mediada por lo objetivo) de la subjetividad vivida, el tema que vive inmediatamente la conciencia religiosa y cuya necesidad como función antropológica establecen las ciencias humanas.

\section{Observaciones finales}

Son sólo tres indispensables complementos, expresados con extrema brevedad.

3.1. Quiero, ante todo, referirme a la evidente incompleción de mis menciones. Al optar por una presentación tipológica, he primado la visión de conjunto y programática. Ya sólo cabían, como expresamente dije, ejemplificaciones. Selectivas, por tanto. En la selección, quedaban inevitablemente peor parados los casos «menos polares" respecto a las coordenadas establecidas por el criterio tipológico elegido. (iAdemás de que cabian, obviamente, otros criterios!) Buscando ahora subsanar algo mi 
incompleción, querría mencionar el meritorio capítulo de aportaciones que supone una copiosa serie de libros escritos por herederos de la tradición de la teología natural. La "reconversión» se ha hecho a veces poco más que en el nombre (dejando, incluso, alguna vez traslucir preocupación apologética). Pero otras veces son esfuerzos valiosos con resultados muy apreciables y enriquecedores. ${ }^{59}$

Otras dos menciones me resultan aquí indispensables. Se trata de casos no poco «atípicos» (aunque no totalmente) para mi tipología: Henri Bergson y Xavier Zubiri. Más que clasificarlos forzadamente, quiero evocar su aportación. El libro (póstumo) de Zubiri, El hombre y Dios, puede ser tenido como su filosofía de la religión. Reciamente intelectualista, pero adverso a la tendencia conceptual-demostrativa de la teología natural, se centra en la «religación" (a la realidad) para acabar encontrándola como experiencia de Dios": un rasgo que, de algún modo, lo aproxima a la religión. ${ }^{60}$ Es, en cambio, la religión en su realidad histórica la que inspiró a $\mathrm{H}$. Bergson la tesis básica de Las dos fuentes de la moral y de la religión (1932). Ya me referi ${ }^{61}$ a lo que estimo ser la apreciación fenomenológica subyacente: la disimetría peculiar de las tradiciones de las religiones de tendencia universal y la (plena) emergencia con los "grandes místicos" de la tendencia a la plena transparencia hierofánica - frente a la más obvia, y nunca eliminable, intransparencia inducida por las concreciones del deseo. La tesis filosófica de «dos fuentes» es, quizá, ruda: suena a hipótesis antropológico-funcionalista. Pero, a mi entender, sugiere vías de reflexión filosófica aún no desarrolladas, de las que difícilmente cabe prescindir al intentar dar cuenta cabal de la historia religiosa de la humanidad y acercarse a un juicio correcto sobre "la verdad de lo religioso".

3.2. Subtitulé como "invitación" mi artículo. Y temo que, en mi intento de presentar en toda su amplitud el campo actual mediante el artificio tipológico, puedo haber resultado disuasorio. Quiero, por ello, añadir que no tengo la dispersión tipificable por lo definitivo. Debería, al contrario, suscitar el proyecto de recoger y sintetizar cuanto sea posible de cada una de las aportaciones. Ante todo, y en relación con mi primer criterio, ¿por qué no podría tomarse como sustantiva tanto la religión como la filosofía?; y dentro de la filosofía, ¿no caben, y no se dan de hecho, posturas maduramente sintéticas? No sugiero, quede ello claro, el superficial eclecticismo; $y$, en tanto en cuanto hayamos de atribuir (con Dilthey) las diferencias a cuestiones de temple vital, serán difícilmente superables... Pero, seguramente, cabe, desde cualquier preferencia bási$\mathrm{ca}$, incorporar espíritu crítico empirista y analítico con miradas racionalmente más generosas respecto al sujeto y a la realidad total. ${ }^{62}$ Como cabe, con esta mayor complejidad de los métodos, lograr propuestas más sugestivamente sintéticas sobre la misma religiosidad..$^{63}$ 
3.3. Paso a mi última observación. Trataría en ella de mirar a la filosofía de la religión desde la misma óptica religiosa. Una mirada así, desde la Ilustración hasta hoy, ha estado de ordinario cargada de recelos. Comprensiblemente: la intervención de la razón sabía a intromisión. Toda tradición religiosa genera, por instinto de defensa, lo que hoy llamamos "fundamentalismo». Y no hay nada más antifundamentalista que la filosofía de la religión. Las agresiones antirreligiosas, físicas o culturales, acaban favoreciéndola por reacción. Pero la serena puesta en cuestión por la razón pone a la religión ante el dilema: o reconsiderarse (evolucionando) o autosegregarse (aislándose del resto de la cultura).

Ahora bien, en tal brete, sólo tiene la religión una salida airosa. Aunque pueda haber excesos rechazables en la intervención de la razón, no es coherente rechazarla en principio como intromisión; pues la razón es lo humano por excelencia. El fundamentalismo es la miseria de la religión, su deshumanización. Las mismas tradiciones religiosas más maduras han desarrollado un amplio ejercicio racional, el que en el mundo cristiano se llama «teología», Ahora bien, para que éste -interior a la tradición, "reflexión de la fe»- sea auténtico, ha de mantenerse en continuo diálogo con la racionalidad "exterior", simplemente humana: con los saberes científicos y las filosofías. Y el campo donde puede darse el encuentro más fecundo y donde, por tanto, puede hoy situarse la clave de la autenticidad de la teología, es precisamente la filosofía de la religión: ${ }^{64}$ un campo de esencial libertad, donde el hecho religioso es estudiado por todos y desde todas las perspectivas y supuestos.

Hay que añadir que la seria instauración de esa "zona franca" puede ser hoy urgente en un país como el nuestro, en que todavía está reciente la memoria de una guerra civil donde el factor religioso fue beligerante; en que aún se ven una y otra vez renacer aguerridos e irracionales brotes de clericalismo y anticlericalismo; en que falta casi absolutamente la institucionalización universitaria, no sólo de la filosofía de la religión sino de la historiografía y las ciencias de la religión. La pronta superación de este vacío tendría una importante función catártica, que toda política inteligente debería comprender y decidirse a promover.

\section{NOTAS}

1. El primero en usar la denominación parece haber sido $\mathrm{S}$. von Storchenau, que, entre 1772 y 1789 , publicó bajo ese título una obra en doce tomos, destinada a mostrar la armonía del pensar racional y la religión revelada. En 1785 se refirió a sí mismo como "autor de la Religionsphilosophie» (datos del exhaustivo estudio histórico de K. Feiereis: Die Umprägung der natülichen Theologie in Religionsphilosophie, Leipzig, 1965. pp. 227-241). En 1797 publicó el kantiano Jakob un Entwurf einer Theorie der Religions. philosophie y, en 1800, el también kantiano I. Berger una Geschichte der Religionsphilo- 
J. Collins en su libro The Emergence of Philosophy of Religion (Yale UP, 1967). De. dica a Hume los caps. 1 y 2, a Kant los caps. 3 a 5 y a Hegel los caps. 6 a 8 . No relaciona esta división con la tipología ternaria de Dilthey.

32. Puedo ya despedir mi inicial clasificación provisional por lenguas, pero no to haré sin expresar la curiosa constatación de una básica correspondencia: en inglés, predomina el tipo $10^{\circ}$ diltheyano; en alemán, el $2 .^{\circ}$ y el $30^{\circ}$; en las lenguas latinas, los abarcables en el que he llamado $\mathrm{A}$. Debo también añadir que he encontrado menos convincentes otros intentos tipológicos. Así, por ejemplo, el de W. Dupré en su excelente Ein/ührung in die Religionsphilosophie, 1985, pp. 99-114: el criterio propuesto es muy complicado (y dependiente de la visión filosófica del autor, a la que después me referiré) y los tipos ("analítico", "reduccionístico", "constitutivo") no son susceptibles de descripciones netas ni de adscripciones verosímiles. El que, por su parte, propone R. Schäffler, en su Religionsphilosophie (1983), no tiene voluntad abarcativa sino selectiva; es claro y oportuno, pero opera sobre una concepción excesivamente amplia de «filosofía de la religión $»$ desde los griegos...

33. Aparecieron en 1957 cuatro libros suyos: Philosophie de la Religion, vols. 1 y 2 , París, PUF; Critique et Religion, Paris, Sedes; Le probleme de Dieu en philosophie de la religion, Brujas, DDB; La foi n'est pas un cri, Tournai, Casterman. Libros que fueron puestos en el Indice de libros prohibidos romano (entonces en sus últimos años de vigencia), por decreto del 17 de junio de 1958 (L'Osservatore Romano, 21-6-1958, que aña. día como comentario: "l'autore è integralmente modernista" y señalaba en el orden filosófico -alejamiento de la escolástica y de santo Tomás-, el origen del error). El proyecto quedó truncado; algo que hay que lamentar profundamente, a la vez que se formula el deseo, en nombre de la religión y de la filosofía, de que casos así no se repitan más. Sobre la obra de Duméry, puede verse el excelente estudio de J. Martín Velasco: Hacia una filosofia de la religión cristiana. La obra de H. Duméry, Madrid, ISP, 1970 (aunque escrito en 1960).

34. Le probleme de Dieu.., ed. cit., pp. 48 y ss. Cfr. J. Martín Velasco, op. cit., pp. 69 y ss.

35. Ver, por ejemplo, Marino, A.: L'herméneutique de Mircea Eliade, París, Gallimard, 1981.

36. Pienso, ante todo, en los coloquios convocados en el Instituto de estudios filosóficos de la Universidad de Roma por Enrico Castelli en los años sesenta y sctenta; publicados por dicha institución $\mathrm{y}$, posteriormente, por el Centre International d'études humanistes (París, Aubier; al menos doce vols.)

37. Panikkar, R.: Myth, Faith and Hermeneutics, Bangalore, Asian Trading Corp, 1979 y Nueva Jersey, Paulist Press, 1983.

38. Como introducción al método de Ricoeur son probablemente lo más útil los ensayos que recogió en el volumen Le conflit des interprétations, París, Seuil, 1969.

39. Sobre el "círculo hermenéutico", ibid.., p. 294.

40. P. Berger y Th. Luckmann, que, como es sabido, han elaborado sus respectivos libros de sociología de la religión a partir del que escribieron en común sobre sociología del conocimiento (La construcción social de la realidad, 1966; trad. cast, Buenos Aires, Amorrortu, 1968), han reconocido siempre sin empacho sus raices filosóficas en la fenomenología, a través del magisterio de A. Schütz.

41. Fierro, A.: Sobre la Religión, Madrid, Taurus, 1979, p. 121. En las páginas siguientes, contrapone netamente la "teorian, que propugna, a la hermenéutica y a su preocupación por la recolección del sentido. "El discurso teórico se consuma con la crítica [...]. No se propone restaurar [...] sino "deconstruir", referir a la alteridad, a las condiciones externas de posibilidad» (p. 123).

42. Ibid., p. 124.

43. La propuesta metódica de Fierro muestra su fecundidad (y su límite) en las rea- 
sophie (referida a pensadores de todas las épocas; cfr. Feiereis, op. cit., p. 1). Kant no llegó a usar el término.

2. De este texto clásico hay una reciente nueva edición, preparada por un equipo dirigido por W. Jäschke, que distribuye más exactamente las redacciones del mismo Hegel y de los alumnos; haciéndose con ello imprescindible en adelante. La edición castellana (preparada por R. Ferrara) ha aparecido simultáneamente en Alianza Ed., Madrid, 1985-1987.

3. Es claro, por ejemplo, de "La educación del género humano" de Lessing. Pero las fronteras son borrosas; y de muchos libros del xuin (como de no pocos del xix y xx) cabe preguntarse bajo qué rúbrica caben mejor.

4. Bueno es recordar que la denominación quedó consagrada sólo en Wolff. La Escolástica incluía a Dios en la metafísica sin hacerlo objeto de una "metafísica especial".

5. Fierro, A.: Sobre la religión, Madrid, Taurus, 1979, caps. 1 y 5 . Lo más denunciable le resulta el artificio estratégico que se despliega cuando desde la noción extrapolada se vuelve sobre el cristianismo para argüir que «es la religión verdadera" (cfr. pp. 238 y ss.). (El valioso libro es, en su tesis más importante, una "teoria del cristianismo", sobre la que reflexionaré más adelante.)

6. La extensión queda mejor justificada cuando se toma en consideración cl hecho de la relación cronológica del surgir de todos estos sistemas en lo que $\mathrm{K}$. Jaspers ha llamado "tiempo-eje», en coincidencia con el surgir del más propio monoteísmo en el Oriente cercano. Volveré sobre ello.

7. Decir esto no es negar las grandes diferencias. Pero tanto en lo personal como en la función política legitimadora, fue real la sustitución.

8. Los conocidos y valiosísimos estudios de G. Dumézil han puesto de relieve la constante estructural tri-funcional de los panteones arios. Ver, por ejemplo, Les dieux des Indoeuropéens, Paris, PUF, 1952.

9. Ver la magnifica introducción («Prolegómenos a una historia de las religiones») de A. Brelich a la Historia de las Religiones dirigida por H.C. Puech (trad. cast. Siglo XXI, vol. I, 1979, pp. 30-97). Clave le resulta el que las religiones dan "un sentido que justifique, posibilite y sostenga los esfuerzos necesarios para seguir existiendo» (p. 67), asegurando asi «al grupo humano el control de aquello que de otro modo aparecería incontrolable, sustrayendo la realidad a la esfera inhumana de la contingencia y confiriéndole una significación humana (p. 58). Encuentro importante la convergencia de estas expresiones con las que en seguida presentaré de la sociología de la religión.

10. La noción ha sido enérgicamente puesta de relieve por $\mathrm{K}$. Jaspers (Origen y meta de la Historia, 1950). Por otra parte, que la división más neta de las religiones es en «étnicas" y "fundadas" (de tendencia universal) es claro para el gran historiador U. Bianchi ("History of Religion", en M. Eliade [ed.].: The Encyclopedia of Religion, vol. VI, MacMiIlan, 1987, p. 4.041 ).

11. La aportación más copiosa ha sido la sociológica. Una bibliografía de más de 23.000 títulos pudo reunirse hasta 1976 (Instituto Fe y Secularidad: Sociologia de la religión y teologia: estudio bibliográfico, Madrid, $1975,474 \mathrm{pp}$, vol. B, $1978,215 \mathrm{pp}$; causas externas hicieron desistir de la prevista continuación).

12. La pretensión "explicativa» no supone estrictamente vínculos causales monodireccionales, sino el establecimiento de correlaciones empíricamente controlables.

13. Ver, sobre todo, el articulo de 1913, «Sobre algunas categorías de la sociología comprensivan, Ensayos sobre metodología sociológica, Buenos Aires, Amorrortu, 1973, pp. $175-221$.

14. La expresión más neta la encontramos en Th. Luckmann: «Das Sinngebende schlechthin des menschlichen gesellschaftlichen Daseins ", decía en la primera redacción alemana (Das Problem der Religion in der modernen Gesellschaft, 1963) como una cuasidefinición de «religión». Desarrollado y matizado en el cap. 3 («La condición antropológica de la religión») de La religión invisible (The Invisible Religion, 1967; trad. cast. de 
M.A. Bermejo, Salamanca, Sígueme, 1973, pp. 51-59), donde cuidadosamente articula, con la básica noción funcionalista hecha sobre «sentido de la existencia», elementos que habria que llamar «sustantivistas" ( cosmos sagrado"). Es aleccionador el paralelo con el proceder de A. Brehlich a que me he referido en la nota 9. Por otra parte, hay que reseñar la reciente llamada de atención sobre el peligro de excesiva elevación teórica que supone el centrar la defínición de "religión" en el término "sentido"; volviendo por los fueros de factores más relevantes para la sociología empirica, como es «podcr». Asi Beckford, J.A.: "The Restoration of "Power" to the Sociology of Religion", en Robins \& Robertson (eds.): Church-State Relations, Oxford, Transactions, 1987, pp. 13.37.

15. Cfr. Mol, H.J.: Identity and the Sacred, Nueva York, MacMillan, 1976. La función se realiza siempre, pero de modo diverso en las religiones étnicas, donde el sujeto es el grupo, y el individuo se identifica por la pertenencia a ćl, y en las "post-axiales" (cfr. nota 10; tomo la pregnante denominación de J. Hick en su reciente libro An Interpretation of Religion, Yale, UP, 1989), donde es el individuo personalizado quien busca la salvación. Precisamente, la tesis central de Luckmann en el libro recién citado es la tendencia, en las sociedades industrializadas, a una situación de gran libertad individual y de eclecti. cismo en la construcción de la propia identidad y de los sistemas de relevancia (cfr. op. cit., pp. 89 y ss.).

16. Durkheim, E.: Les formes élémentaires de la vie religieuse, 1912. Ha sido ordinario atribuir a este libro, junto con Weber, la paternidad de la sociología de la religión del sigio $\mathrm{xx}$.

17. Vale la pena recordar literalmente el célebre pasaje: «Una religión es un sistema solidario de creencias y de prácticas relativas a las cosas sagradas, es decir, separadas, interdictas; creencias y prácticas que unen en una misma comunidad moral llamada Iglesia a todos aquellos que se adhieren a ellas" (Las formas elementales de la vida religiosa, Madrid, Akal, 1982, p. 42). Como ya recordé antes (nota 14), Th. Luckmann ha buscado «articular», dentro del ámbito más general de la "religión "como donación de sentido, "un dominio formado por símbolos que representan un rasgo "estructural" esencial de la vi. sión del mundo como un todo - a saber, su propia jerarquía interna de significadon ( $L a$ Religión invisible, p. 68). Éste, que otras veces llama "cosmos sagrado", es el que constituye las religiones más estrictamente tales. A. Fierro (Sobre la religión, op. cit., cap. 4) sugiere oportunamente el concepto de "práctica simbólica» como el genérico que podría abarcar tanto a las religiones clásicas como a sus análogos funcionales (ver también 231 y ss.).

18. Otto, R.: Das Heilige, 1917 (trad. cast., F. Vela: Madrid, Alianza [reed.], 1980). Ha quedado como clásica su descripción de «lo numinoso" como Mysteritum fascinans/tremendum.

19. La primera gran exposición metodológica es la de G. van der Leeuw al final de su Fenomenología de la religión, 1933 (trad. cast. de E. de la Peña, México, FEC, 1964, pp. 642 y ss.). Excelente obra de conjunto dedicada al método: Waardenburg, J.: Reflections on the Study of Religion, La Haya, Mouton, 1978. Tras un buen estudio de los clásicos (y especialmente de Van der Leeuw), recoge las críticas que cabe hacerles y sugiere el camino de un "new style phenomenological research» (menos subjetivo, más situado, interdisciplinar). A destacar el valor, en todo el ámbito hístórico-fenomenológico, de la tradición holandesa. Una clara presentación del método también en Martín Velasco, J.: Introducción a la fenomenología de la religión, Madrid, Cristiandad, 1976, pp. 46-83.

20. Eliade, M.: Traité d'histoire des religions, 1949. La edición castellana (Madrid, Crìstiandad, $1981^{2}$ ) pone acertadamente como subtítulo: "Morfologia y estructura de lo sagradon, que era el título del primer capítulo. La gran base de conocimientos histórícos que poseía el autor ha quedado patente en su monumental Historia de las creencias e ideas religiosas (cuatro volúmenes, de los que ha quedado sin aparecer el 3, 2) (trad. cast. Madrid, Cristiandad, 1978-1983).

21. Hay una cierta tendencia a pensar que se ha dicho todo cuanto se dice: «lo no- 
profano". Pero "profano", literalmente es lo no-sagrado (exterior al fanum, templo). Se evita la tautología diciendo, en vez de "profano", lo sotro", lo no-ordinario. Pero, ¿es suficientemente discriminatorio? Sólo la actitud vivida da acceso a ese indefinible inicial que se está queriendo sugerir.

22. Eliade, M.: Traité.... pp. 24-25. En las copiosas descripciones de constelaciones hierofánicas que constituyen el cuerpo de la obra, quedan dibujadas, bajo la multiplicidad aparentemente caótica, unas claves de unidad. El cielo y la tierra son como dos supremas matrices hierofánicas en la estructuración del cosmos sagrado. (Algo que respalda bien la conocida tipologia de la religiosidad auránica/ctónica»). Importante recoger aún la aportación del capítulo final, que pone al simbolo en relación con la hierofanía: «prolongación de la hierofania» (p. 373). «El simbolismo revela la necesidad humana de prolongar al infinito la hierofanización del mundo [...]" (p. 375).

23. Martín Velasco, J.: op. cit., pp. 109 y ss.

24. Ver, por ejemplo, Waardenburg, J.: Reflections on the Study of Religion, p. 135. Tras mantener que "todas las expresiones humanas [...] tienen que ver con intenciones por las que se hace patente un sentido [...]", anade: "Phenomenologically speaking, in religion the object of the intention has become transcendent to man and has an absolute quality for the participant(s) [...]». Los subrayados son míos. Encuentro aleccionadora la vecindad con el proceder de Luckmann a que me referí en la nota 17.

25. Conserva valor el clásico análisis diferenciador de B. Malinowski: Science, $\mathrm{Ma}$ gic and Religion, 1925 (trad. cast. Barcelona, Ariel, 1974). Sobre "magia y religión», un buen desarrollo en Widengren, G.: Fenomenologia de la Religion, 1945 (trad. cast., Madrid, Cristiandad, 1975, pp. 1.16).

26. Algo en lo que, de nuevo, encontramos interesantes convergencias con la consideración más científica. Ver, por ejemplo, la expresión de A. Fierro (Sobre la Religion, pp. 163-165) donde "Dios" podría ser "la cifra del supremo interés", una especie de id quo maius desiderari nequit...

27. Entiendo - permitaseme esta interpretación personal-que es la percepción conjunta de estos dos rasgos lo que constituye el núcleo (denominable «fenomenológicon) de la tesis (filosófica) de Bergson en su Les deux sources de la morale et de la religion, 1932. El "gran místico" en su experiencia excepcional "toca" el fondo misterioso de lo real (-máxima transparencia hierofánica). Remodela (aunque sólo parcialmente) con su influjo la tradición hierofánica precedente, en la que se expresaba una búsqueda de sentido más tosca, una religiosidad más primitiva, vinculada a metas concretas del deseo.

28. Una excelente argumentación en favor de la especificidad del tratamiento filosófico de la religión (en su distinción frente al científico), en Bueno, G.: El animal divino. Ensayo de tuna filosofía materialista de la religión, Oviedo, Pentalfa, 1985. Es también muy lúcido y honesto su reconocimiento de que son posibles diversas filosofías de la religión, en función de la divcrsidad general de las tendencias filosóficas. La peculiar filosofía "materialista" del autor condiciona, desde luego, mucho sus posiciones en el tema religioso; y no será posible discutir las consecuencias sin remontarse a una discusión sobre las premisas.

29. Un criterio así habia ya parecido como fundamental a J. Hessen (Religionsphilosophie, vol. I, Essen/Friburgo, H. Chamier, 1948, pp. 19 y ss.). La obra, añadirê, perspicaz y muy erudita (aunque demasiado circunscrita al ámbito germanófono), podría ser mencionada como típica del tipo A, que completa la fenomenología con una filosofía afín, en este caso la axiológica. (Lo que Scheler y Hartmann han hecho para la ética, querría Hessen hacer para la religión, vol. 1, p. 359.)

30. Dilthey, W.: Teoria de las visiones del mundo (1911) (trad. cast., J. Marias: Madrid, Alianza [reed.], 1974).

31. La relevancia de los tres autores ' $y$ de las diversas orientaciones filosóficas que encarnan) para la filosofía de la religión fue muy oportunamente subrayada por 
lizaciones que ofrece: por ejemplo, puntualización de la consideración del cristianismo como ideología (pp. 139 y ss.), valor y criterios para evaluar una «práctica simbólica» (pp. 183 y ss.). Una ponderación crítica realicé, en su momento, en Sistema, 40 (enero 1981), pp. 130-140.

44. La filosofía de Fierro lo tiene, como ha podido apreciarse. Más patente es aún en otra reciente aportación de autor español, la de G. Bueno (a quien ya me referí antes, nota 28). Su original libro tiene el mérito de recordar con amplia erudición la relevancia de la simbólica zoomórfica en la historia de las religiones -un aspecto, hay que reconocer, un tanto descuidado en la misma emorfología de lo sagrado" de Eliade. Pero de ahí a la tesis ontológica que mantiene como religión verdadera a la zoolátrica ("primaria"), sólo se puede pasar por la decidida opción epistemológica empirista, que sólo podrá reconocer como referentes reales a los "númenes" animales (ver, acumulativamente, pp. 147, 154 y 164), La opción es llamativamente injusta para las grandes religiones "post-axiales" (antes, notas 10 y 15), para Bueno «terciarias»: ya siempre híbridos de religión y filosofía metafísica, sólo "dialécticamente verdaderas en tanto culminan en la destrucción de toda religión positiva, en la iconoclastia y el ateísmo* (p. 228).

45. Recogida en Flew, A. y MacIntyre, A. (eds.).: New Essays in Philosophical Theo$\log y$, Londres, SCM, 1955 (intervenciones de A. Flew, R.M. Hare, B. Mitchell e I.M. Crombie).

46. Antiseri, D.: Filosofia analitica e semantica del linguaggio religioso (1969) (trad. cast.: El problema del lenguaje religioso, Madrid, Cristiandad, 1976).

47. Las contribuciones más enriquecedoras en esa dirección pueden haber sido las de I.T. Ramsey: Religious Language (1857); I.M. Crombie: The Possibility of Theological Statements (1958); W.A. Christian: Truth-Claims in Retigion (1962; ésta, al igual que la anterior, recogidas en Santoni, R.E. [ed.]: Religious Language and the Problem of Religious Knowledge, Indiana UP, 1968); Jeffner, A: The Study of Religious Language, Londres, SCM, 1972.

48. Despertó, probablemente, el nuevo interés por el tema J.N. Findlay al responder afirmativamente a la pregunta que tomó en 1949 como título: Can God's Existence be disprooved? (articulo publicado inicialmente en Mind y recogido en los New Essays, ya citados en la nota 45, pp. 47-56): era una especie de "antiargumento ontológico" basado en la inevitabilidad religioso-teísta del concepto de Ser Necesario junto con su esencial inviabilidad para la filosofía lógico-empirista. Aparte de los replanteamientos históricos relativos al Proslogion y tradición subsiguiente, iniciados en 1960 por N. Malcolm, la defersa del concepto en reciente lógica modal y una consiguicnte revalorización del argumento han sido tarea protagonizada por A. Plantinga: ver su «Necessary Being" en la obra colectiva de la que él mismo es editor, Faith and Philosophy (Michigan, Eerdmans, 1964, pp. 97-108) y, sobre todo, su libro The Nature of Necessity, Oxford UP, 1974.

49. Quizá el exponente más sígnificativo de las nuevas orientaciones sea R. Swinburne. Ver sus libros: The Coherence of Theism (1977), The Existence of God (1979), Faith and Reason (1981) (todos en Oxford, Clarendon Press). Contrarios al teismo: Mackie, J.L.: The Miracle of Theism, Oxford, Clarendon Press, 1982; O'Hear, A.: Experience, Explanation and Faith, Londres, Routledge, 1984.

50. El nombre lo puso K. Nielsen, y el representante más caracterizado es D.Z. Phillips en libros publicados en 1965 (The Concept of Prayer) y 1970 (Faith and Philosophical Enquiry). Una discusión crítica de sus ideas puede verse en $\mathrm{J}$. Sábada: Lengtaje filo. sófico y filosofía analitica, Barcelona, Ariel, 1977, pp. 66-78.

51. Sábada, J.: Lecciones de filosofia de la religión, Madrid, Mondadori, 1989, pp. $45-46,58$ y 109 .

52. Dupré, W: Einführung in die Religionsphilosophie, Berlín/Colonia/Maguncia, Kohlhammer, 1985. Además del uso de conceptos tipicamente hegelianos (Spannung, Ver. 
mittlung...), se revela la inspiración en la preocupación por la cultura como marco. Ha escrito también Religion in Primitive Cultures: A Study in Ethnophilosophy, La Haya, Mouton, 1975.

53. Ibid., p. 163.

54. Ibtd., p. 142. Notar que esta noción, interior al mundo cultural, viene después de otra buscada en perspectiva de «la historia de la evolución" (pp. 131-140).

55. Sobre Blondel habia publicado Duméry en 1948 su primera obra importante: La Philosophie de l'Action. Essai sur l'intellectualisme blondelien (París, Aubier). El espiritu blondeliano es, sin duda, el que le condujo a superar a Husserl desde Husserl, en su original "cuarta reducción".

56. Jaspers, K.: La fe filosófica ante la revelación (trad. cast. G.Díaz y Díaz, Madrid, Gredos, 1968). La parte 7.a clímax del libro, es un abordaje rebosante de humanidad de la cuestión: « $i$ Pueden coincidir la fe filosófica y la fe revelada?». La respuesta tiende a una dolorosa negativa que sin embargo, no cierra la cuestión. Frente al positivismo - el gran mal de la edad cientifica y tecnológica- los dos creyentes, el filósofo y el religioso, mantienen su situación de hermanos/adversarios.

57. Sobre las acifras", partes $4 .^{a}$ y $5 .^{a}$ del libro (op. cit., pp. 104-460). Por otra parte, tanto ese tema como los inscparables de la «existencia posible», la «libertad y la atranscendencia», son temas centrales de la filosofía de Jaspers como tal: ver la parte $3 .^{\text {a }}$ de su obra capital, Filosofta (1932). Cabe concluir, como antes al considerar el «idealismo objetivo», que tampoco la filosofía de la religión hecha desde el «idealismo de la libertad» puede ser simplemente sectorial.

58. El copioso discurso actual sobre "el sentido de la existencian tiene, ciertamente, el peligro de ser poco riguroso - provocando con ello la crítica radical de las mentes más positivistas. No hay muchos intentos explícitos de precisión semántica. Permítase. me remitir al que - como aportación provisional- presenté en el seminario «Racionalidad cientifica y convicción creyente*, publicado en los protocolos de dicho seminario (Madrid, Instituto Fe y Secularidad, 1980, pp. 77-81). Algo después, Sauter, G.: " "Sinn" und "Wahrheit". Die Sinnfrage in religionstheoretischer und theologischer Sicht", en Rendtorff, T. (ed.): Religion als Problem der Aufklärung, Gotinga, Vandenhoeck \& Ruprecht, 1980, pp. 69-106.

59. Como tales creo hay que tener, incluso reconociendo sus limitaciones, la obra (ya antigua) del gran Karl Rahner: Hörer des Wortes: Zur Grundlegung der Religionsphilosophie, Munich, 1941 (una reelaboración [por J.B. Metz] apareció en 1963); y la reciente de B. Welte: Religionsphilosophie, Friburgo, Herder, 1978 (trad. cast., Barcelona, Herder, 1982). Por el expresivo sentido paradójico que ello tiene, me resulta éste un lugar adecuado para rezordar el reciente alegato de L. Kolakowski: Si Dios no existe..., Londres, 1982 (trad. cast., Madrid, Tecnos, 1985), en favor de una reconsideración de ciertos temas de la teologia natural.

60. De la religión, hay que reconocerlo, apenas habla el libro El hombre y Dios, (Madrid, Alianza, 1984). Salvo, precisamente, en la alusión etimológica (điscutible como tal, según es sabido) de su palabra central, "religación". Pero esta sola relación es ya valiosa: podría hacerse, pienso, una "fenomenología de la religación», que preparara la toma de postura filosófica del libro. La filosofía del hombre religado no es, ciertamente, sectorial; pero ya otros autores actuales (Dupré, etc.) mantienen, como hemos visto, la vinculación de filosofía de la religión y filosofía primera.

61. Véase antes, p. 111 y nota 27 . Otro valor muy apreciable de la aportación bergsoniana es la vinculación (sin fusión) en que pone las dimensiones religiosa y ética de la existencia humana en ese nivel superior de ambas que es ala 2 . $^{\text {a }}$ fuente".

62. Valga citar dos buenas muestras reçientes de esta búsqueda de complementación metodológica. La Religionsphilosophie de R. Schäffler (Friburgo/Munich, K. Alber, 1983) propone, en su capítulo final, unir fenomenologia, análisis del lenguaje y búsqueda tras. 
cendental del concepto de Dios (pp. 218 y ss.). El libro, ya póstumo, de H.G. Hubbeling. Principles of the Philosophy of Religion (Assen/Maastricht, Van Gorcum, 1987), ensambla una presentación muy al día de los temas de la Philosophical Theology (caps. 2 y 3) con una copiosa y cuidada selección de observaciones "fenomenológicas" sobre la estructura de la actitud religiosa (cap. 4).

63. Tal, la propuesta de «Religious Pluralism», muy matizadamente elaborada, en la que desemboca el último libro de John Hick: An Interpretation of Religion, Yale UP/MacMillan, 1989 , pp. 233 y ss., dignisima culminación de una vida dedicada a la filosofía de la religión.

64. Una teología que tome coherentemente en scrio la dimensión que suele llamarse «teología fundamental» queda ya cerca de la filosofia de la religión; puede, incluso, ser filosofía de la religión, en la medida en que el creyente, que reflexiona su fe, logre "empezar su reflexión" desde aquel fondo de sí mismo donde es, antes que nada, un ser humano. Quizá nunca es eso posible en plena medida; a ello cabe, en todo caso, acercarse mediante el diálogo y la autocritica. Son buenos ejemplos de lo fecundo del acercamiento libros como el de X. Pikaza: Experiencia religiosa y Cristianismo, Salamanca, Sígueme, 1981, y el de A. Torres Queiruga: La revelación de Dios en la realiza. ción del hombre, Madrid, Cristiandad, 1987. 